\title{
ESTIMATION OF RAIN ATTENUATION AT MICROWAVE BANDS IN NIGERIA
}

\author{
G. A. Akinyemi ${ }^{1}$, J. A. Falade ${ }^{2}$ and L. B. Kolawole ${ }^{1}$ \\ ${ }^{1}$ Department of Physical Sciences, Redeemer's University, Ede, Nigeria \\ ${ }^{2}$ Department of Electrical/Electronics Engineering, University of Ilorin, Ilorin, Nigeria
}

The paper is received on June 6, 2018

\begin{abstract}
The ever-increasing demand on satellite communication systems has resulted in lower frequency bands becoming increasingly congested. The available radio wave frequencies above $\mathrm{Ku}$-band are prone to signal attenuation due to rain. The rain data obtained from the Tropospheric Observatory Data Acquisition Network (TRODAN) of the Nigeria Space Research and Development Agency (NASRDA) located across the geographical zones of Nigeria were used to analyse the rain attenuation from $99.99 \%$ to $99.9 \%$ availability (i.e., $0.01 \%$ to $0.1 \%$ unavailability) of time. From the study, at $0.01 \%$ of time needed for radio communication system, rain rate values $\mathrm{R}_{0.01}$ were found to vary from $125 \mathrm{~mm} / \mathrm{hr}$ to $46.98 \mathrm{~mm} / \mathrm{hr}$. The $\mathrm{R}_{0.01}$ values across the studied locations were subsequently used to estimate rain attenuation using the International Telecommunication Union-Radio (ITU-R) model. Attenuation results show corresponding increase as the path length of the terrestrial links increases. The attenuation due to the horizontally polarized waves is large compared to the attenuation of the vertically polarized waves at all frequencies and in all the locations of the study. It is also evident that availability requirement increases with attenuation.
\end{abstract}

Key Words: tropical climate, rain attenuation, rain height, ITU-R model, path length, TRODAN.

\section{Introduction}

In the design of a satellite system, the quality of services to be provided (e.g. video, voice or data transmission) is the primary factor to be considered. The usual constraints are variables such as cost, the atmospheric influences and the needed technology. At the commencement of satellite communication, service providers 
operated in the lower frequency bands such as the L-, S- and C-bands because at these frequencies, galactic and man-made noise are minimal. Similarly, atmospheric absorption and induced impairments are generally insignificant [1]. However, the rapid growth in telecommunications, miniaturization of communication equipment and much demand for bandwidth has resulted in congestion at lower frequency bands [2]. In order to compensate for the large demand, it has become necessary for the radio link designers to develop microwave systems operating at higher frequency bands such as the $\mathrm{Ku}-\mathrm{Ka}-$ and V-bands [3]. Unfortunately, propagation at and above about $10 \mathrm{GHz}$ suffers serious attenuation due to hydrometeors such as atmospheric gases, cloud, fog, snow, hail glaze and rain absorption and scattering of the energy density of the incident electromagnetic wave by individual drops of rain [4,5]. While attenuation can be caused more frequently by cloud and gases, it is more pronounced by rain [6,7]. Electromagnetic waves passing through raindrops at any of afore-mentioned bands will be absorbed, scattered or transmitted through the medium. Furthermore, rain changes the polarization of the electromagnetic wave as it propagates through it, which as well causes degradation in the quality of the received signal [8]

The magnitude of attenuation caused by rain depends on parameters such as the size of raindrops, rain temperature, drop velocity, polarization, rain rate, drop orientation and transmitting frequency [3]. In temperate regions, propagation of radio signals at frequencies above $10 \mathrm{GHz}$ is susceptible to the adverse effects of rain while even at lower frequencies, around $7 \mathrm{GHz}$, these effects become of great concern in tropical, subtropical and equatorial regions of the world [4], where rainfall is characterized by the high intensity (rain rate), the enhanced frequency of rain occurrence and the presence of large raindrops.

\section{Rain Attenuation Prediction Models}

Attenuation due to rain can be measured quite accurately by means of satellite beacon signals and radiometers. However, since propagation experiments are carried out only in a few locations in the world and for a limited number of frequencies and link 
geometry, their results cannot be directly applied to all sites [9]. Hence, researchers have developed a number of rain attenuation models using available meteorological data. Notable among these models are: Simple attenuation model (SAM), Australian model, Brazil model, Bryant model, Garcia model, Karasawa model, Svjatogor model and the ITU - R model to mention a few.

The ITU-R P.618-12 model is widely accepted around the world and hence usually served as benchmark against the other developing models for reliability and especially for cases where measured data are not available [10]. In order to compute the slant-path rain attenuation using point rainfall rate, the procedure of step-by-step calculation of the ITU-R model can be obtained from [11], [12].

\section{Research Methodology}

The rain data used for this work was obtained from the Tropospheric Observatory Data Acquisition Network (TRODAN), a project of National Space Research and Development Agency (NARSDA) under the Centre for the Atmospheric Research, (CAR) Ayingba, Nigeria.

Table 1. Stations in each Geopolitical Zones

\begin{tabular}{|l|l|l|}
\hline S/N & Geopolitical Zone & TRODAN Stations and Locations \\
\hline 1 & South-West (SW) & $\begin{array}{l}\text { Yaba-Lagos, Akungba, Redemption Camp- } \\
\text { Mowe }\end{array}$ \\
\hline 2 & South-East (SE) & Owerri, Enugu \\
\hline 3 & South-South (SS) & Port Harcourt, Uyo \\
\hline 4 & Middle-Belt (MB) & Minna, Makurdi \\
\hline 5 & North-West (NW) & Sokoto, Kano \\
\hline 6 & North-East (NE) & Yola, Maiduguri \\
\hline
\end{tabular}

The total rain accumulation and rain rate data were collected from 13 stations. These stations were carefully selected across the six geopolitical zones of Nigeria so that 
the weather and geophysical structure of each zone are well represented as tabulated in table 1. The Map of Nigeria showing these stations is presented in Figure 1.

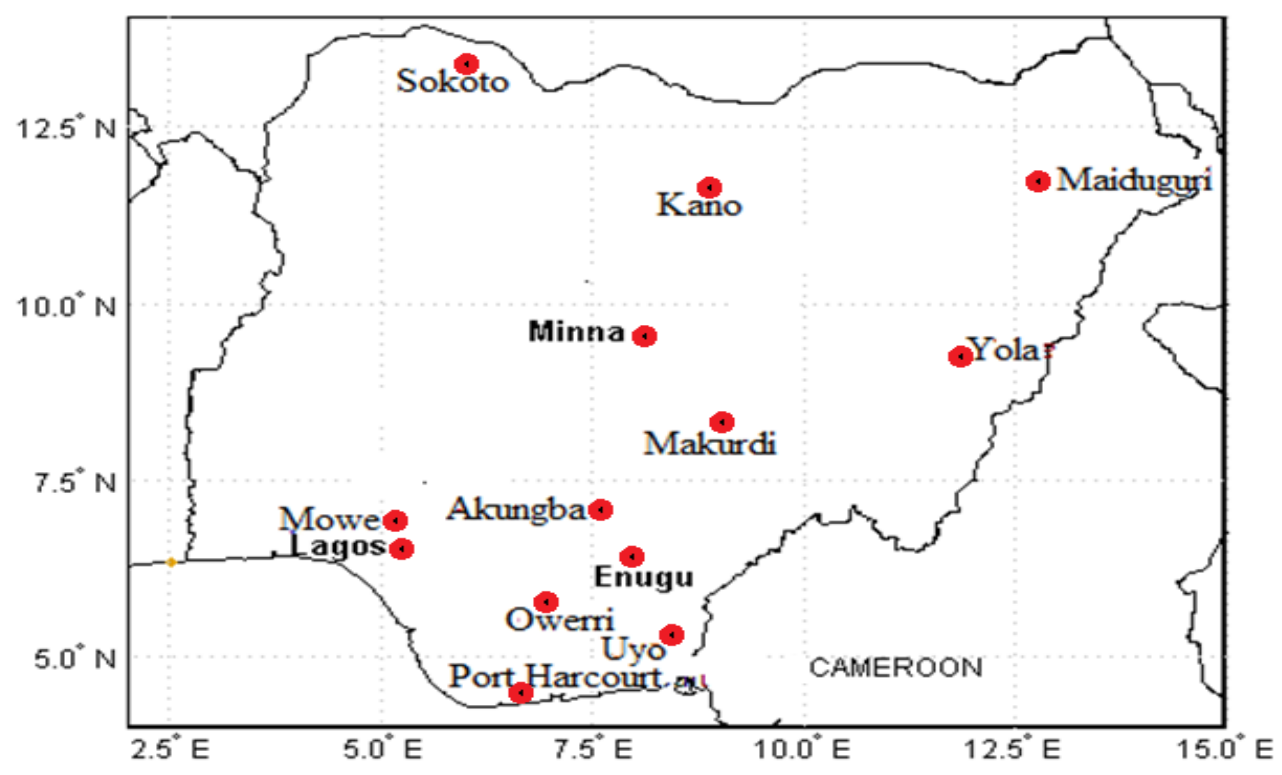

Figure 1. Distribution of TRODAN stations used for the study

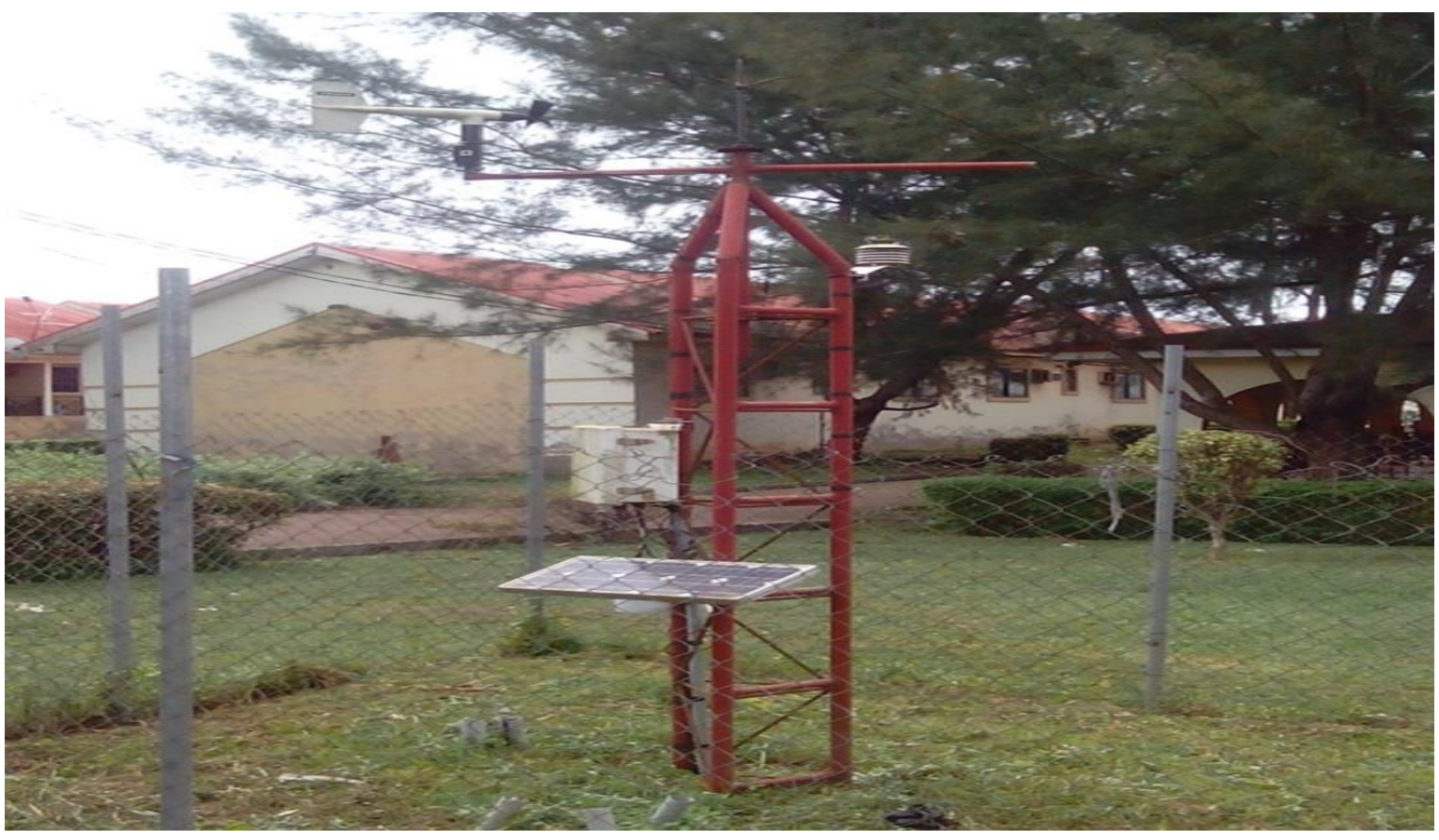

Figure 2: The TRODAN Station at Redeemer's University temporary campus, Mowe.

Figure 2 shows a typical TRODAN equipment located at each of the station where the rainfall data used for the study were obtained. The equipment consists of sensors for 
the measurement of atmospheric variables such as temperature and humidity, solar power system to ensure uninterrupted power supply, measurement and control system and the data logging system.

Rainfall intensities measurements are made by a tipping bucket rain gauge which stands $146 \mathrm{~mm}$ high as part of TRODAN setup in all the sites. The rain gauge has sensitivity of about $0.1 \mathrm{~mm}$ and a data acquisition unit along with other sensors in the other different units as shown in figure 4. For the rain gauge measurement, the rain water is collected in a standard funnel and is converted into drops of equal sizes. The number of drops collected in every 10 seconds is registered electronically and finally averaged over 5 minutes. The Analog to Digital Converter (ADC) voltage of each channel is continuously sampled and stored in digital form, together with the date and time of each rain gauge tip. The calibration of the rain gauge is maintained by cleaning the capillary. The overall reliability of the gauge is extremely high due to the simple drop-forming mechanism. The reliability was ensured to be high by keeping it clean so that dust particles do not obstruct the free flow of water.

\section{Rain Height}

To correctly estimate rain attenuation along the slant-path of a satellite link, an understanding of rain height is a requirement. The method, adopted by ITU-R, assumes the rain structure to be uniform from the ground level to the Zero Degree Isotherm (ZDI) height; simply termed the effective rain height, $h_{R}$. Often the empirical formula is used to estimate the value of $h_{R}$ due to scarcity of measured data. Most of the referenced rain height experiments were done in Europe and Asia, and very little data is available in Africa except in West Africa [13], [14], [15], [16]. This research work uses the latest ITU Recommendation P.839-3. This model is widely employed to calculate the average rain height. The mean rain height above mean sea level is expressed as:

$$
h_{R}=h_{o}+0.36 \mathrm{~km}
$$

where $h_{o}$ is the average annual $0^{\circ} \mathrm{C}$ isotherm height. 


\section{Results and Discussion}

Variation of Attenuation with Frequency- Knowing the level of attenuation due to rain in a location gives the radio link planners information about the extent to which the transmitted signal will be degraded in the presence of rain. The choice of operating frequency of a radio link is influenced by the rain attenuation and availability stipulations for the service on offer.

From Figure 3, it is observed that for a given percentage availability, attenuation shows corresponding increase as the frequency of operation increases in all the stations under study. For instance, considering horizontal polarization, at $15 \mathrm{GHz}$, attenuation in Yaba, Lagos is about $49.1 \mathrm{~dB}$. For the same location, availability requirement, and polarization at $75 \mathrm{GHz}$, the attenuation has increased to about $365 \mathrm{~dB}$. It is also evident that the horizontally polarized electromagnetic wave experiences the highest attenuation, followed by the circularly polarized signal, while the vertically polarized signal gives the least attenuation. These results have a similar trend as the results obtained by [3] and those of [17].

Considering all the stations under study, Port Harcourt suffers the highest attenuation at all frequencies and percentage availabilities, closely followed by Owerri and Uyo. Comparing with Port Harcourt, at $75 \mathrm{GHz}$, and considering horizontal polarization, Uyo is $7 \mathrm{~dB}$ less, while Owerri is $5 \mathrm{~dB}$ less. For circular polarization, Uyo and Owerri suffer less degradation by $6.9 \mathrm{~dB}$ and $5 \mathrm{~dB}$ respectively, while for vertical polarization; they are $9.2 \mathrm{~dB}$ and $7.2 \mathrm{~dB}$ off, respectively. Akungba significantly suffer the least attenuation at all frequencies and percentage availabilities even though it does not have the smallest elevation angle. This may be due to its low $\mathrm{R}_{0.01}$ value. At $15 \mathrm{GHz}$, the upper band of the Ku-band, the lowest attenuation value is $16 \mathrm{~dB}$ while the maximum is about $49 \mathrm{~dB}$. Also, at $40 \mathrm{GHz}$, the upper band of the Ka-band, the minimum attenuation obtained is about $101.7 \mathrm{~dB}$ and the maximum is about $309 \mathrm{~dB}$; while at $75 \mathrm{GHz}$, the upper band of the $\mathrm{V}$-band, the minimum and maximum attenuation are about $153 \mathrm{~dB}$ and $419 \mathrm{~dB}$ respectively. All these comparisons are made for $99.99 \%$ 
availability ( $0.01 \%$ unavailability of time) and horizontal polarization. Hence, $16 \mathrm{~dB}$ and $49 \mathrm{~dB}$ can be considered as the minimum and maximum attenuation levels respectively for Ku-band at $99.99 \%$ availability requirement in Nigeria since the selection of the locations used in this study cuts across the nation. Also, at Ka-band, the minimum attenuation level is about $102 \mathrm{~dB}$, while the maximum can be taken as $309 \mathrm{~dB}$.

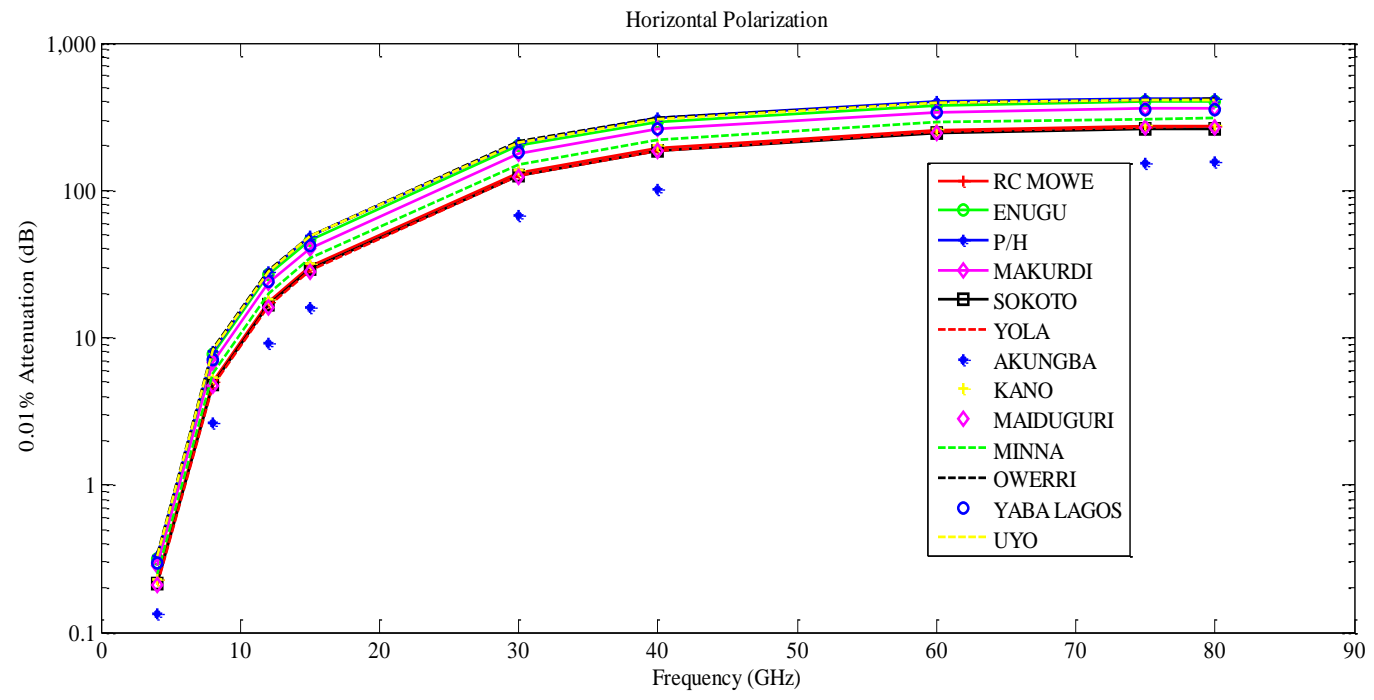

Figure 3a: Attenuation at $0.01 \%$ exceedence for all stations for Horizontal polarization

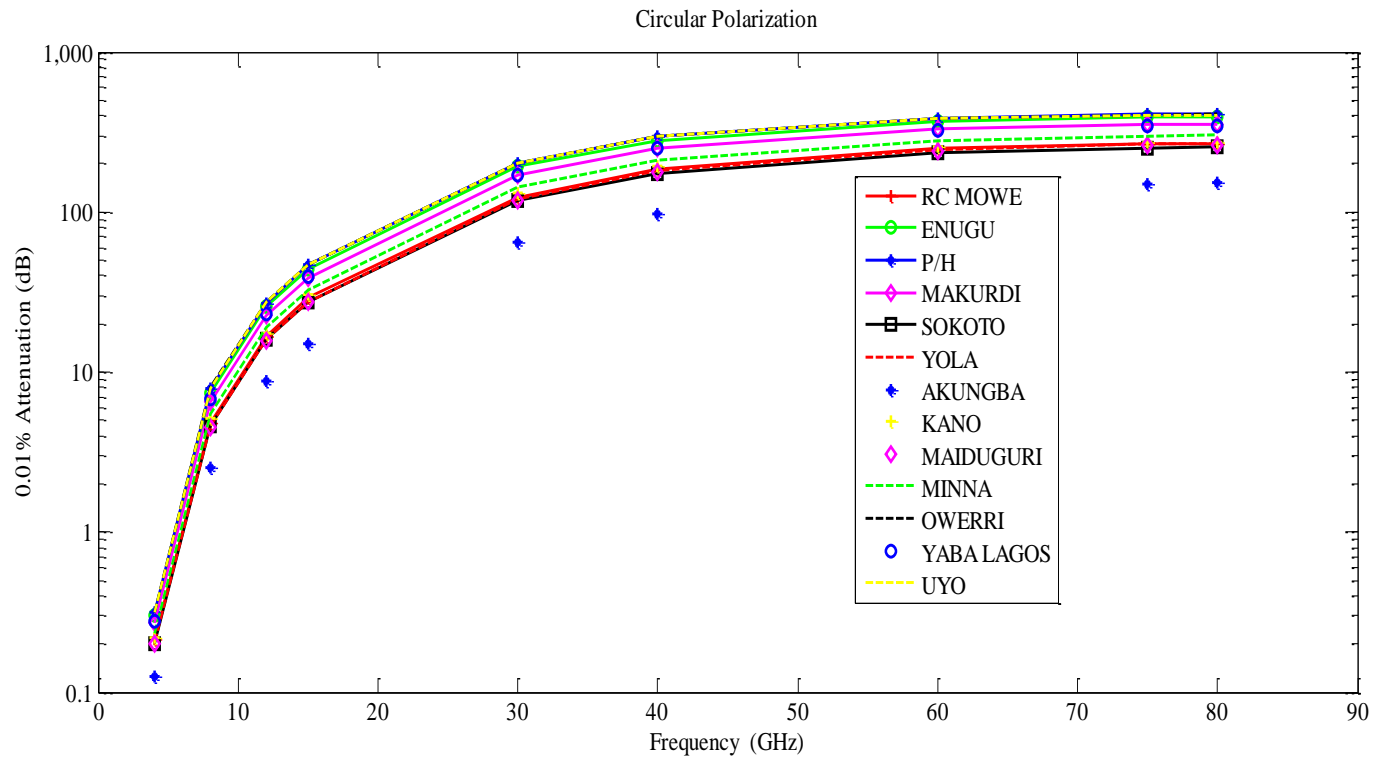

Figure 3b: Attenuation at $0.01 \%$ exceedence for all stations for Circular polarization 


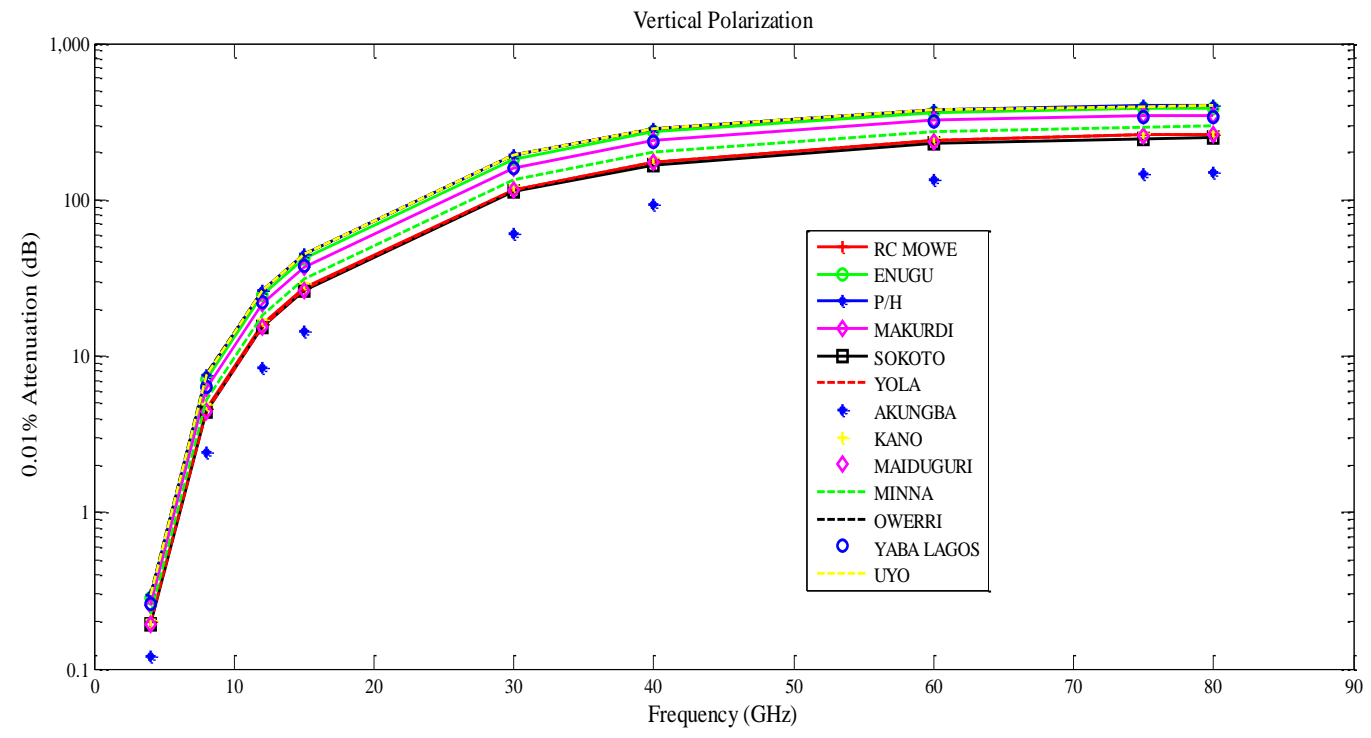

Figure 3c: Attenuation at $0.01 \%$ exceedence for all stations for Vertical polarization

\section{Variation of Effective Path Length}

Figure 4 (a-c) shows the variation of the effective path length with the frequency.

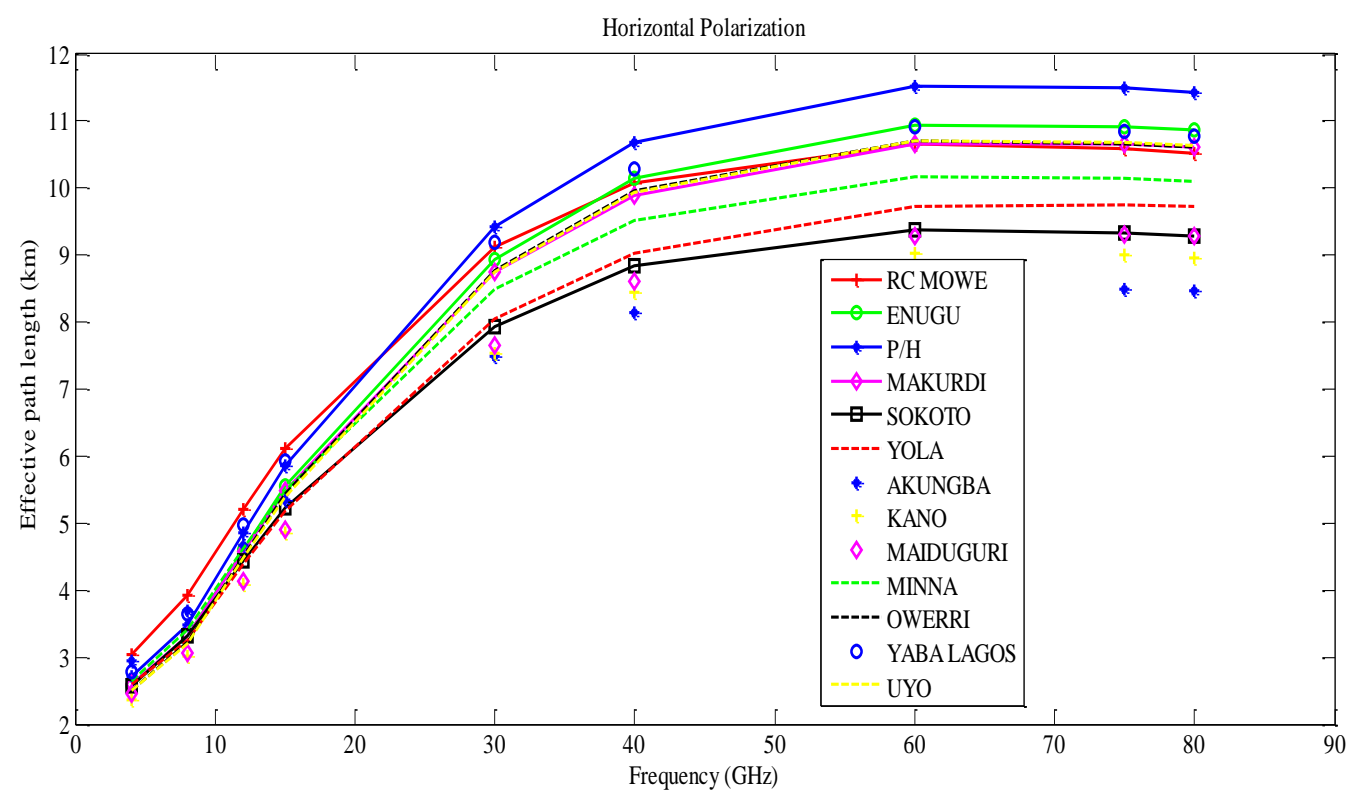

Figure 4a: Effective path length for all stations for Horizontal polarization

It is observed from Figure 4 (a-c) that for a given location, the effective path length increases as the frequency increases from the C-band up to the Ka-band and begins to decrease gradually as frequency increases from the V-band. It is observed also, that the effective path length for the horizontal polarization is longer than that of the circular polarization and the vertical polarization has the shortest effective path length. 


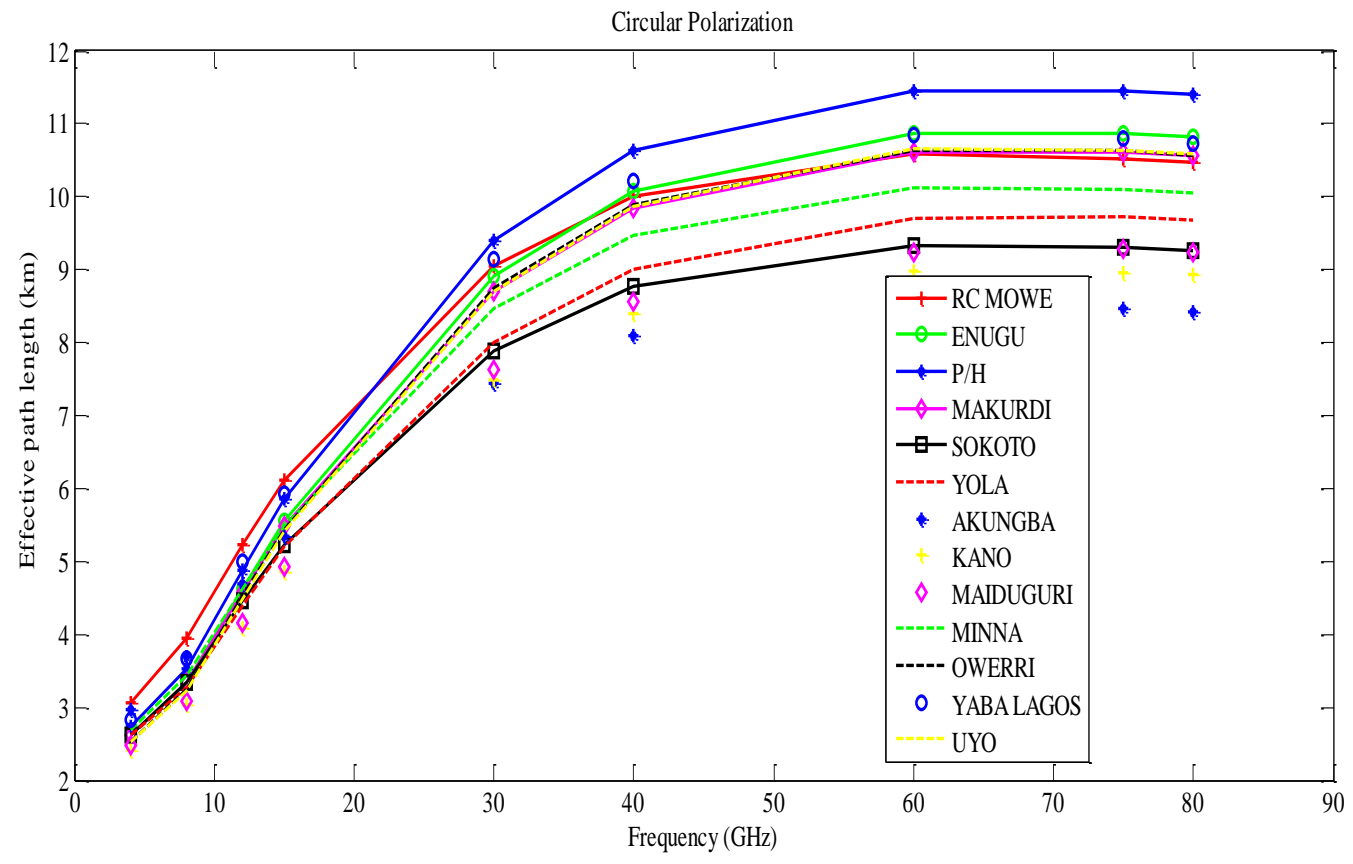

Figure 4b: Effective path length for all stations for Circular polarization

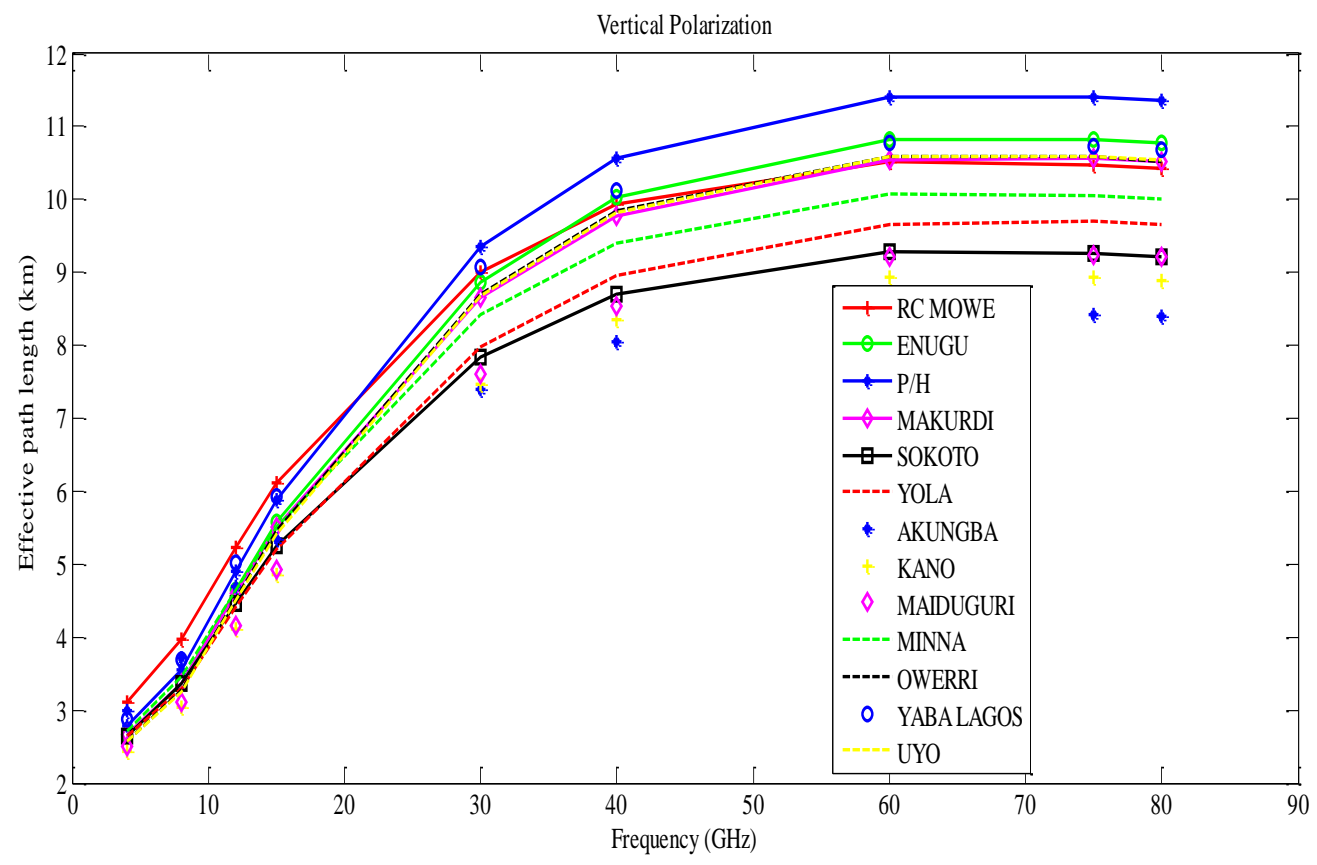

Figure 4c: Effective path length for all stations for Vertical polarization 


\section{Variation of Rainfall Attenuation with Availability}

The most important input for system designers is the rain rate exceeded at the critical level of $0.01 \%$ of an average year (availability level of 99.999) which translates to an outage of about 52 minutes in a year. In this work, attenuation was determined for probabilities ranging from $0.001 \%$ to $5 \%$ (availability from 99.999 to $95 \%$ ). Figures 5 a and 5 b show the variability for the lower and upper bands for the C-bands, it is evident from the results that attenuation level at lower frequency bands is very insignificant even at high availability requirements, compared with the level of attenuation at upper frequency bands, for example, attenuation values ranging from $0.27 \mathrm{~dB}$ to $0.34 \mathrm{~dB}$ are recorded for all the locations at $4 \mathrm{GHz}$ even at a critical availability level of $99.99 \%$.

This observation further buttresses the insignificance of the level of attenuation due to hydrometeors at lower frequency bands as reported in literature [3, 17]. It is also evident from the Figures that attenuation increases with availability. It is obvious too from these results, that attenuation variability is location dependent. It is also glaring that as frequency increases, attenuation level also increases.

It can be deduced that areas with the same rain rate may not necessarily have equal attenuation due to the fact that geographical locations have impacts on rainfall attenuation.

Increasing the satellite operating frequency will boost the antenna gain. By increasing the frequency, the larger gain of the antenna can be used to either increase the effective isotropic radiated power or reduce the antenna size for the same radiated power.

Figures 5 to 9 show that operating at the Ka- and V-bands requires a considerable amount of compensation for attenuation compared to operating at lower bands. 


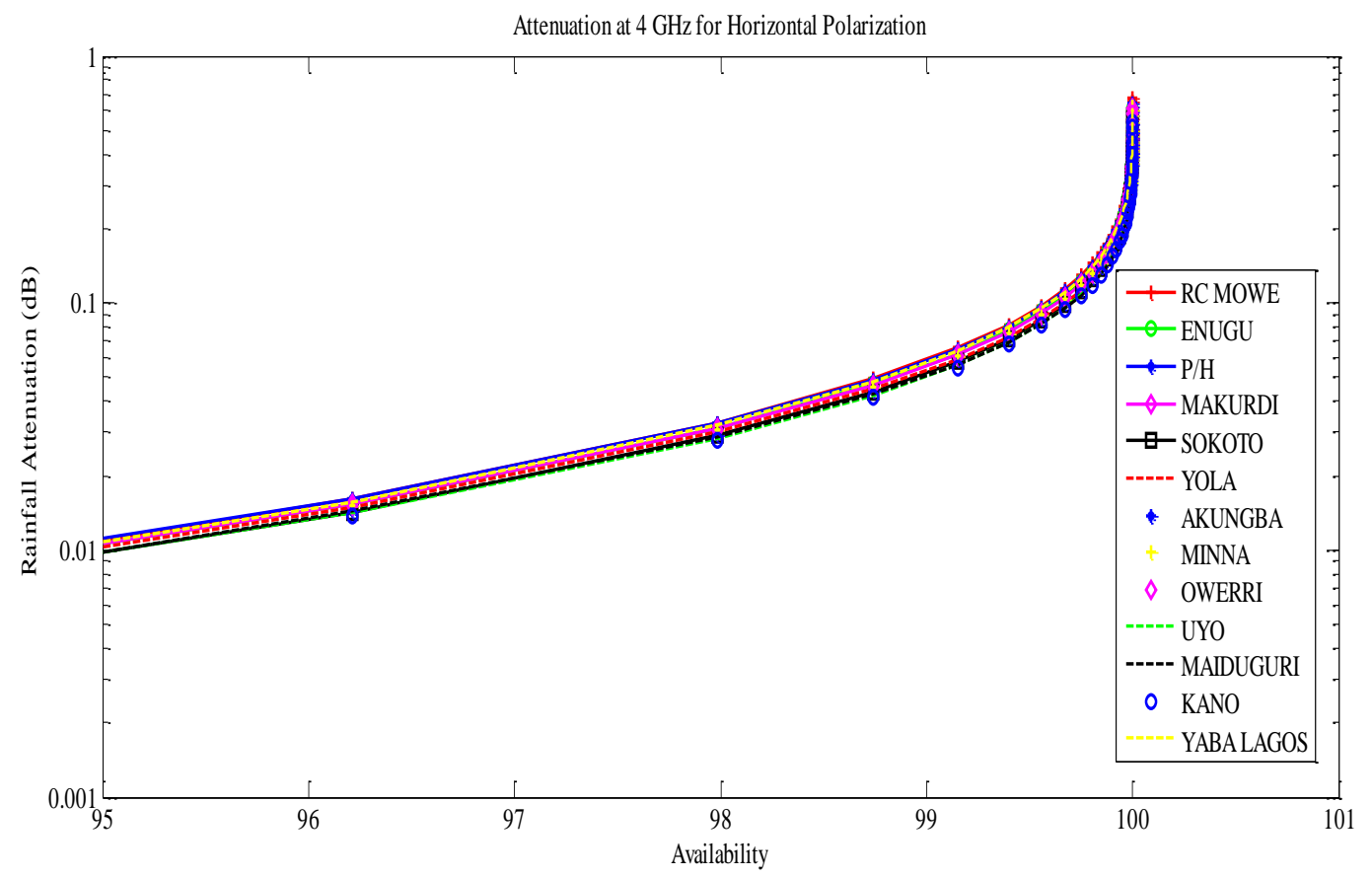

(a)

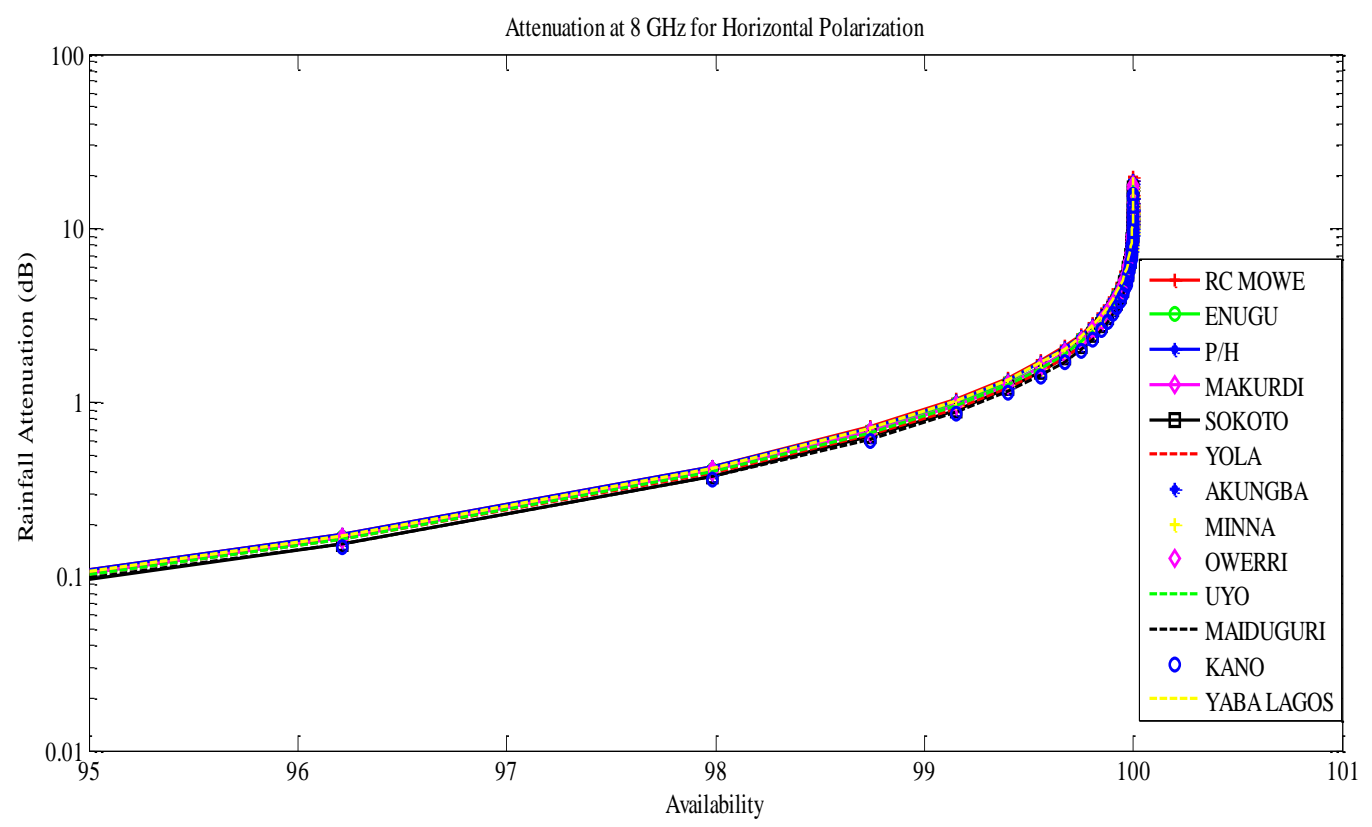

(b)

Figure 5. Attenuation at C-band for Horizontal polarization at for all stations at $4 \mathrm{GHz}$ and (b) $8 \mathrm{GHz}$ 


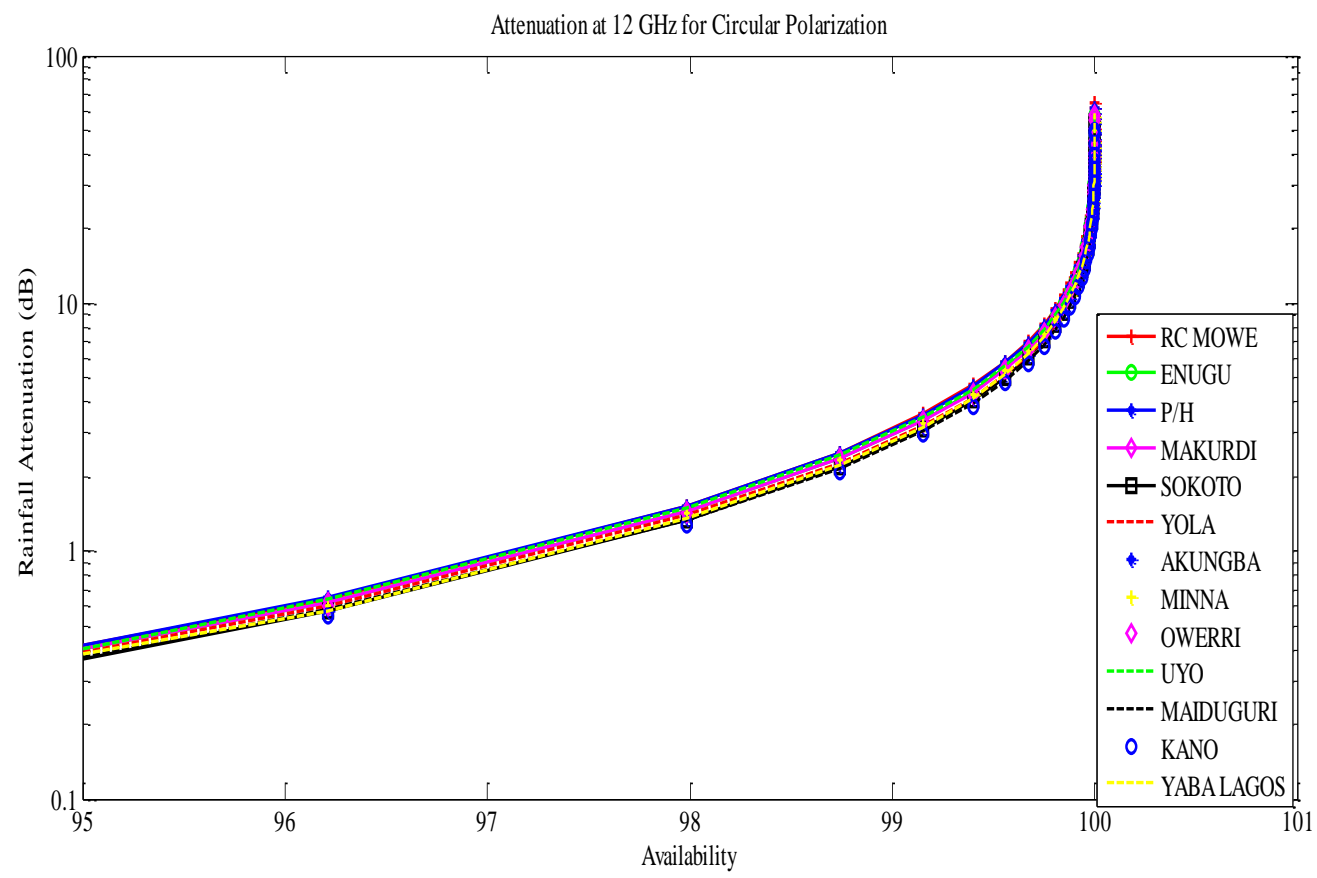

(a)

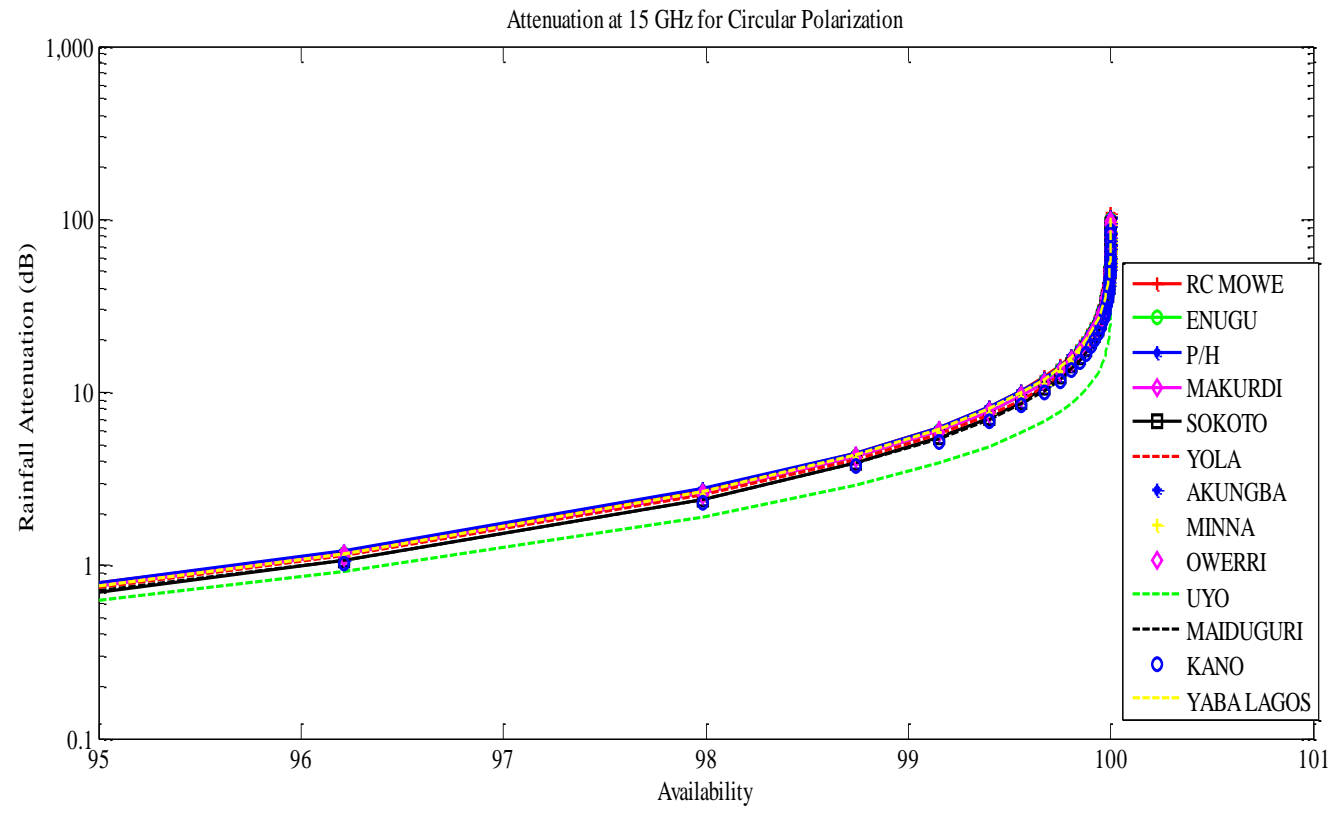

(b)

Figure 6. Attenuation at Ku-band for circular polarization for all stations at (a) $12 \mathrm{GHz}$ and (b) $15 \mathrm{GHz}$ 


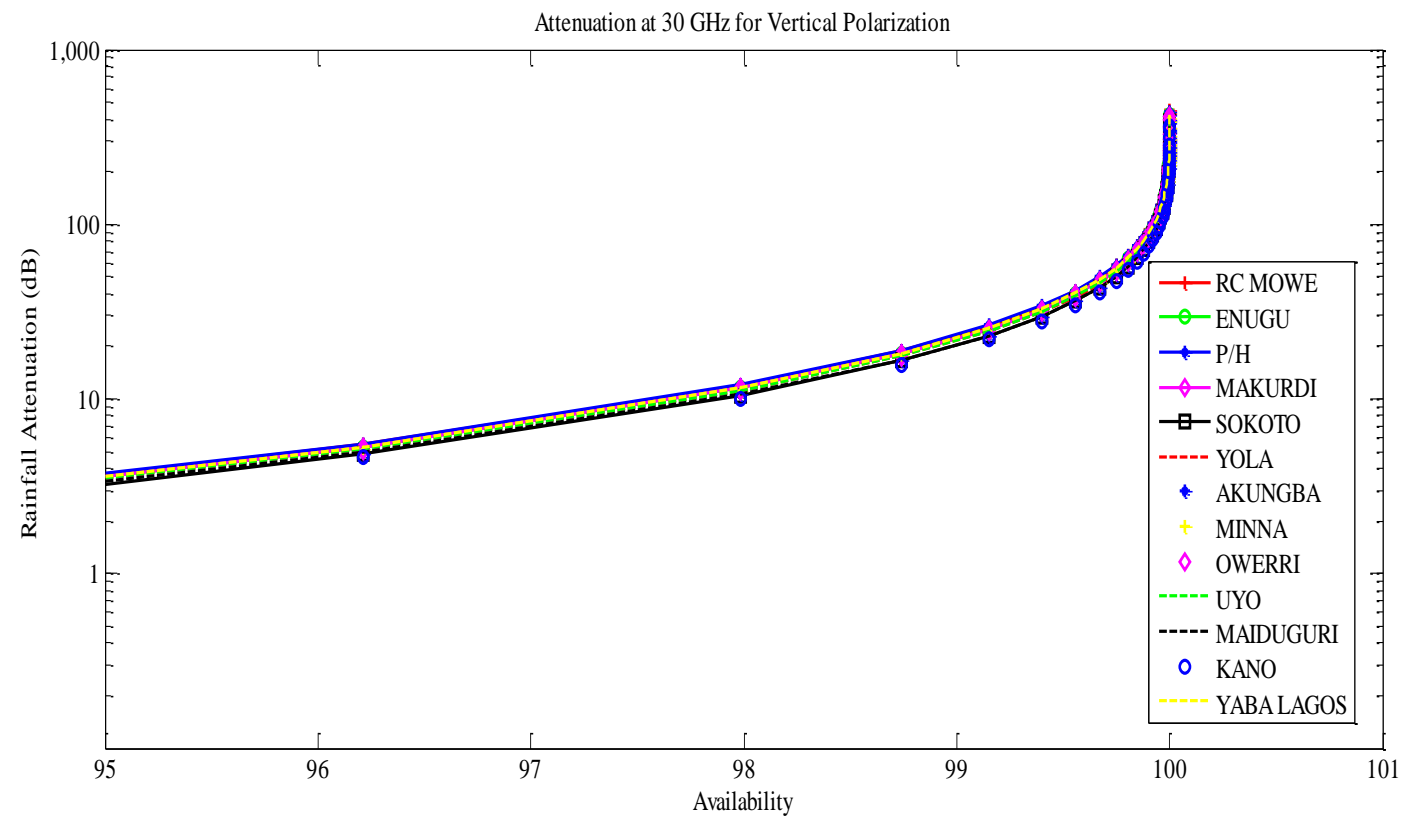

(a)

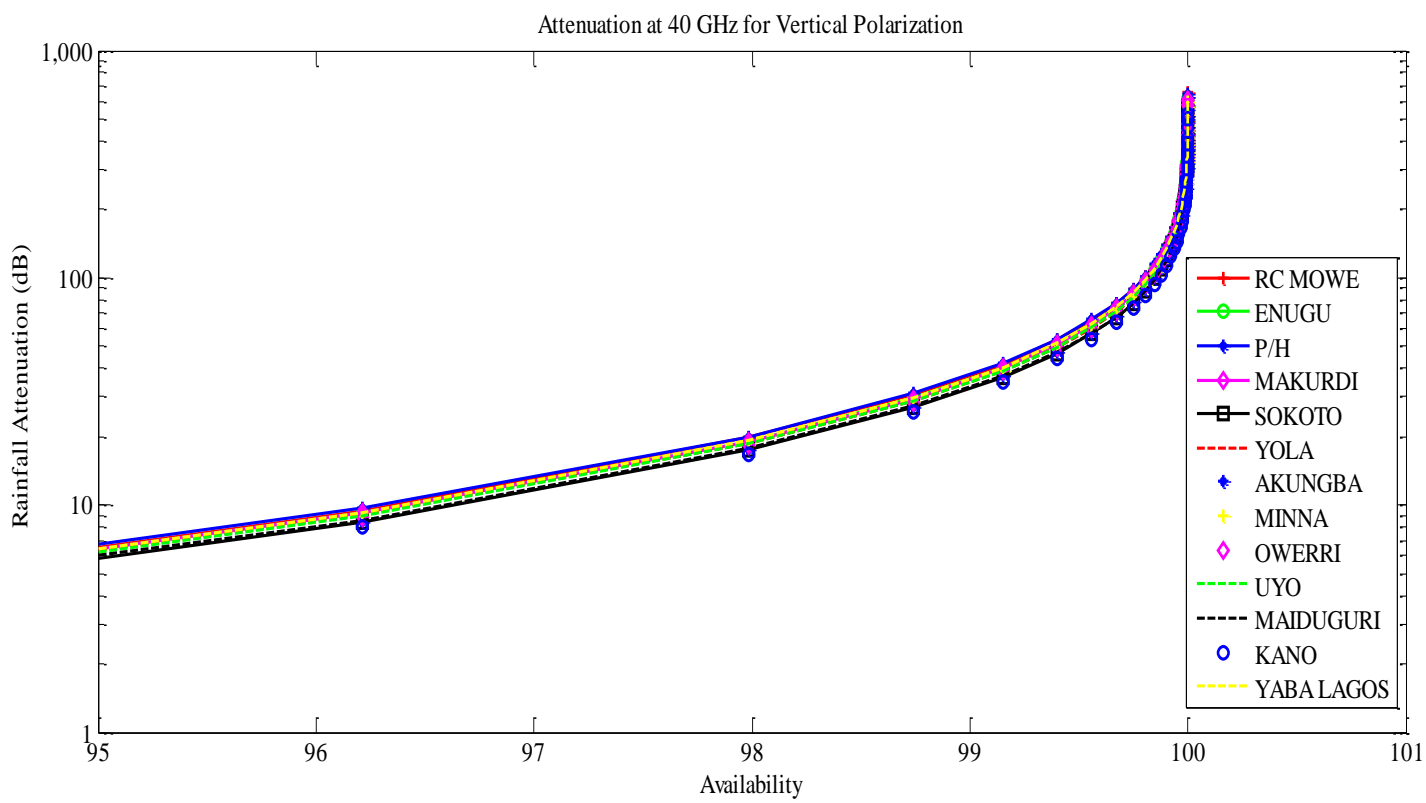

(b)

Figure 7. Attenuation at Ka-band for vertical polarization for all stations at (a) $30 \mathrm{GHz}$ and (b) $40 \mathrm{GHz}$ 


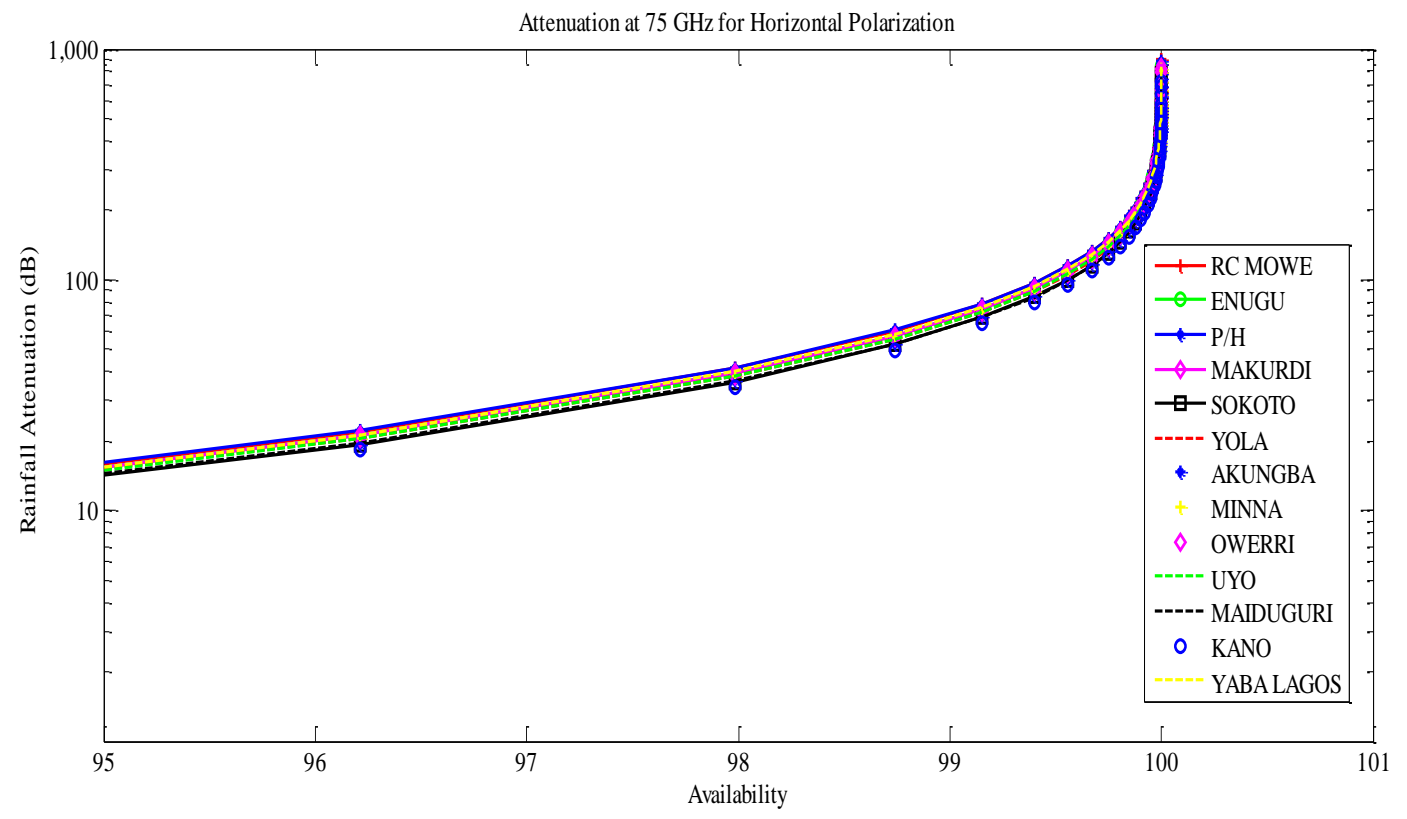

(a)

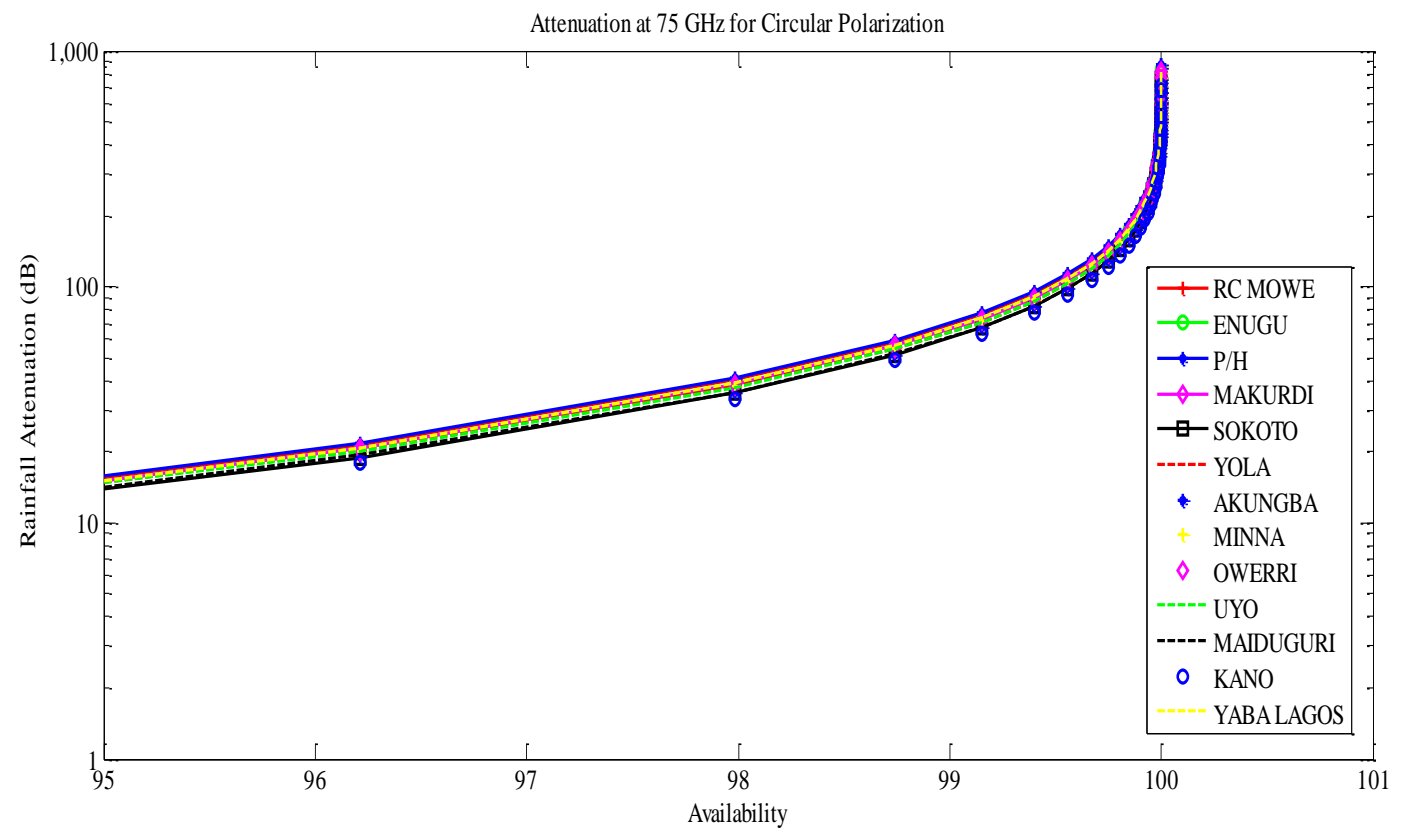

(b)

Figure 8. Attenuation at V-band for (a) horizontal (b) circular at $75 \mathrm{GHz}$. 


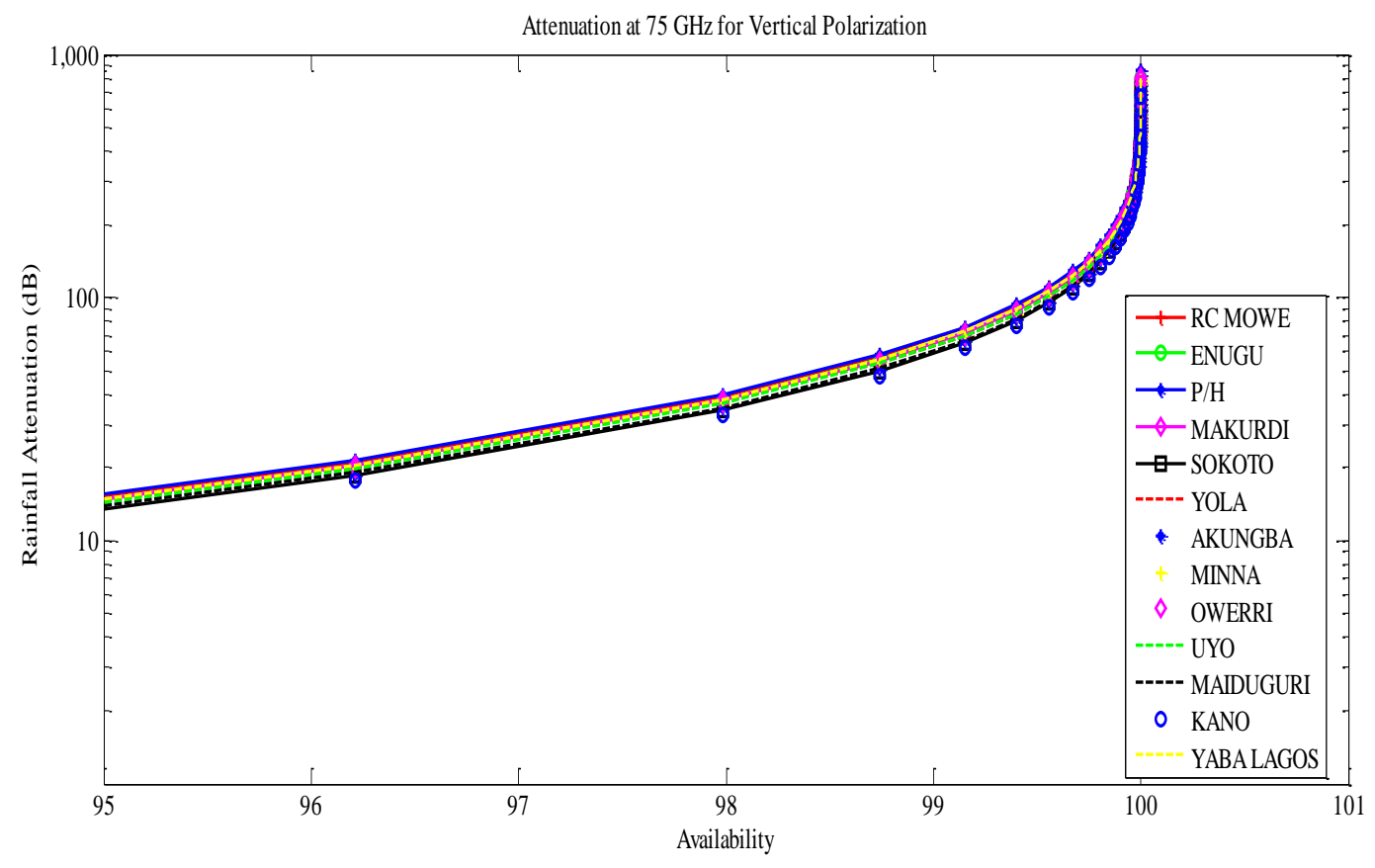

Figure 9. Attenuation at V-band for vertical at $75 \mathrm{GHz}$.

\section{Conclusion}

The characteristics of the satellite used in this work are those of Nigeria Communication Satellite (NIGCOMSAT-R1), which operates on C-, Ku- and Ka-bands but projections are made into the V-band. Across all frequency bands, rainfall attenuation and effective path length have been determined for satellite links in Nigeria. Considerations were made for link availabilities from $95 \%$ up to $99.99 \%$ of the time. It is noted that for a particular given percentage availability, attenuation increases with effective path length as well as the frequency of operation is increased. It is noted also, that the severity of the degradation of the propagating signal increases with increasing availability. For a given location, the effective path length varies directly with the frequency.

\section{References}

1. Freeman, R.L., Radio System Design for Telecommunications. Hoboken, New Jersey: John Willey and Sons, 2007. 
2. Panagopoulos, A.D., P. D. M. Arapoglou, and P. G. Gottis, "Satellite Communications at $\mathrm{Ku}, \mathrm{Ka}$, and $\mathrm{V}$ bands: Propagation impairments and mitigation techniques", IEEE Communications Surveys and Tutorials, Vol. 6, No. 3, pp. 2 - 14, 2004.

3. Malinga, S. J., P. S Owolawi, and T. J. O. Afullo, "Estimation of Rain Attenuation at $\mathrm{C}, \mathrm{Ka}, \mathrm{Ku}$ and $\mathrm{V}$ Bands for Satellite Links in South Africa", PIERS Proceedings, Taipei, March 25-28, pp. 948 - 958, 2013.

4. Moupfouma, F., "Improvement of a rain attenuation prediction method for terrestrial microwave links", IEEE Transactions on Antenna and Propagation, Vol. 32, No. 12, pp. 1368-1372, 1984.

5. Oyinloye, J. O., "The troposphere in tropical and sub-tropical latitudes, Handbook on Radio Propagation for Tropical and Sub-Tropical Countries", Proceeding of URSI Committee on Developing Countries, pp. 77-79, 1987.

6. Omotoso T. V., "Studies of Propagation impairments for fixed satellite communication links at the microwave frequencies in Nigeria", Ph.D Thesis submitted to Covenant University Otta, Nigeria, 2008.

7. Adrian J. T., "A study of the raindrop size Distribution and its effect on Microwave Attenuation", Ph.D Thesis, Electronics and Electrical Engineering, University of Bath, 2011.

8. Nelson, R.A., "Rain-How it Affects the Communications Link", Applied Technology Institute, Berkshire Drive, Riva, Maryland, Vol. 97, pp. 53-56, 2000.

9. Cost Project 255, "Radio wave Propagation Modeling for Satcom Services at Ku band and Above Final Report, ESA Publication Division, 2002

10. Abayomi, Y., and N. H., Hajikhamis, "Rain Attenuation Modelling and Mitigation in the Tropics: Brief Review", International Journal of Electrical and Computer Engineering, Vol. 2, No. 6, pp. 748-757, 2012. 
11.International Telecommunication Union, Propagation data and prediction methods required for the design of Earth-space telecommunication systems. Recommendation ITU-R P. 618-12, Geneva, Switzerland, 2015

12. Mandeep, J. S., "Slant path rain attenuation comparison of prediction models for satellite applications in Malaysia”, Journal of Geophysical Research, Vol. 114, D17108, 2009.

13. Mondal, N.C. and S. K., Sarkar, "Rain height in relation to $0^{\circ} \mathrm{C}$ isotherm height for satellite communication over the Indian subcontinent", Theoretical and Applied Climatology, Vol. 76, pp. 89-104, 2003.

14. Ong, J.T., K. L., Timothy, F. B. L., Choo, and W. L., Carron, "Effective rain height statistics for slant path attenuation prediction in Singapore", Electronic Letters, Vol. 36, No. 7, pp. 661-663, 2000.

15. Parshoatam, S., I. S., Hudiara, and Singh, M.L. "Estimation of effective rain height at $20 \mathrm{GH}_{\mathrm{Z}}$ at Amritsar (tropical region)", IEEE Transaction on Antennas and Propagation, Vol. 55, No. 5, pp. 1463-1465, 2007

16. International Telecommunication Union (2015) ITU-R P. 839-3

17. Athanasios, D.P., M. Pantelis-Daniel, and G., Anayotis, "Satellite Communications at ku, ka, and V-Bands". Propagation Impairments and Mitigation Techniques, Vol. 6, No. 3, 2004.

\section{For citation:}

G. A. Akinyemi, J. A. Falade and L. B. Kolawole. Estimation of rain attenuation at microwave bands in Nigeria. Zhurnal Radioelektroniki - Journal of Radio Electronics. 2018. No. 8 Available at http://jre.cplire.ru/jre/aug18/18/text.pdf

DOI 10.30898/1684-1719.2018.8.18 